\title{
PROPOSICIONES APROBADAS POR LA ASAMBLEA
}

La Comisión de Coordinación e Iniciativas del Cuarto Congreso de Catedráticos de Literatura Iberoamericana propuso los siguientes acuerdos:

$1^{\circ}$ Dése un voto de cordial simpatía y profundo agradecimiento a la Universidad de La Habana, por haber patrocinado este Congreso y por las múltiples atenciones que ha tenido para con todos los delegados. Extiéndase igual manifestación al Ministerio de Educación por la hospitalidad de que ha sido objeto el Congreso, en las ocasiones en que esa dependencia del poder público cubano ha tenido como huéspedes a los delegados. Exprésese el agradecimiento de la Asamblea al Municipio de La Habana, a la Comisión organizadora de la conmemoración del primer centenario del nacimiento de Enrique José Varona; a la prensa y a todas las entidades y personas que han contribuido a la brillante celebración de este acto y a la grata permanencia de los delegados en esta espléndida ciudad.

$2^{\circ}$ Exprese el Congreso su simpatía a los delegados que por circunstancias especiales no pudieron concurrir a él ; particularmente a los que por su precaria salud no les fué posible estar físicamente presentes en las asambleas, como Gabriela Mistral, Baldomero Sanin Cano y Alfonso Reyes, indiscutibles maestros en la materia objeto de la reunión.

$3^{\circ}$ 'Hágase saber a la U. N. E. S. C. O. el interés con que fué recibido el mensaje que, por conducto de Antonio Castro Leal, hizo llegar a la Asamblea, por el espiritu que la anima, de cooperar a 
esta organización haciendo traducir los libros más importantes de la literatura iberoamericana.

$4^{\circ}$ Otórguese, asimismo, un voto de agradecimiento y simpatía a las universidades y colegios que enviaron delegados al Congreso o dieron facilidades a sus profesores para que concurrieran a las juntas y a todas las instituciones extranjeras que cooperaron a que se realizaran estas labores.

$5^{\circ}$ Habiendo rebasado los cien años de edad, el ilustre maestro don Federico Henríquez y Carvajal, el Congreso le rinde un cálido voto de admiración y respeto, asociándose así a todas las personas físicas y morales que han participado en los homenajes tributados hasta ahora a tan eminente hombre de letras.

$6^{9}$ Agradézcasele a la Universidad Nacional Autónoma de México la contribución que ha venido aportando al Instituto, consistente en el trabajo de impresión de la Revista Iberoamericana, e invítese a las universidades y colegios de los Estados Unidos e Iberoamérica para que cooperen en alguna forma a mantener vivo el espíritu que anima a este Instituto.

$7^{0}$ Otórguese un voto de reconocimiento al doctor Raimundo Lazo, a su digna esposa y a todos sus colaboradores y colaboradoras, por la tarea realizada para la organización de este Congreso y por la forma en que se han llevado a cabo sus asambleas.

$8^{\circ}$ Exprésese igualmente el reconocimiento del Instituto a los funcionarios del mismo que durañte más de cinco años mantuvieron viva su organización, en medio de múltiples dificultades, señores Arturo Torres-Rioseco y J. R. Spell, Dorothy Schons, Nina Weissinger, J. T. Reid, J. A. Crow, M. Erickson, J. E. Englekirk, Gastón Figueira, Mariano Picón-Salas, Carlos García Prada, Julio Jiménez Rueda, Francisco Monterde, Manuel Pedro González y a todos los que en una forma $\mathfrak{u}$ otra aportaron sus consejos o su ayuda personal a la realización de los fines del Instituto.

90. Procúrese que los gobiernos, colegios, universidades y academias, museos y demás instituciones de cuttura del Continente adquieran suscripciones de la Revista o se inscriban como socios protectores, para que ella alcance la difusión necesaria en nuestros países 
iberoamericanos, siquiera en la misma proporción que ya tiene en los Estados Unidos.

10. Pídase a las universidades y colegios de Enseñanza Superior en este Continente que, en ocasión del centenario de Varona, se den conferencias o cursillos sobre la vida y obra de tan destacado pensador.

II

Tomada en cuenta la iniciativa presentada por los delegados Raimundo Lazo y Juan J. Remos, sobre la mejor organización del Instituto, la Comisión de Coordinación e Iniciativa propuso que se modifique el artículo octavo de los Estatutos y normas del Instituto, en los siguientes términos:

Octavo.-La Junta Directiva del Instituto se encargará en cada país de América:

I.-De organizar una entidad filial al Instituto que coopere con la junta, para que se realicen los fines en la redacción de la Revista y sirva de medio de comunicación de la entidad central con los profesores de literatura, hombres de letras y personas interesadas en su labor, y ayude también en la organización de los congresos enviando personalidades representativas a ellos;

II.-En los países de América en los que residan miembros del Instituto se confiará a ellos la organización de las filiales a que se refiere el inciso anterior;

III.-En los que no haya miembros activos del Instituto, la Directiva organizará directamente estas filiales, $y$

IV.-La Mesa Directiva queda facultada pará expedir el reglamento que norme la acción de estas filiales.

III

Turnada a la Comisión de Coordinación e Iniciativas la propuesta de los señores Luis-Alberto Sánchez, Andrés Iduarte y Juan 
Lizcano, sobre motivos de literatura popular y folklore, la comisión propone a la Asamblea la adopción de los siguientes votos:

1 Recomiéndese por los medios más convenientes a los gobiernos, universidades y centros culturales iberoamericanos, la fundación de centros de estudios folklóricos que contribuirán con sus aportaciones a la enseñanza de las literaturas nacionales;

$2^{\circ}$ Solicítese a los gobiernos, universidades y centros de cultura de cada país, por el órgano más adecuado, la creación de premios anuales para los mejores trabajos de investigación folklórica, y

$3^{\circ}$ Solicítese igualmente de estas entidades, la formación de catálogos de las producciones literarias manuscritas inéditas que conserven; la depuración y corrección de los textos respectivos; e intercambio de copias fotográficas de los mismos y la publicación, en revistas adecuadas o en libros, del resultado de estos trabajos.

IV

Con relación a una de las proposiciones contenidas en la ponencia del señor Lizaso, ya que las otras han sido aprobadas unánimemente por la Asamblea, la comisión propone se apruebe la declaración que sigue:

Unica: el Congreso Internacional de Literatura Iberoamericana, ratifica las declaraciones de los Congresos anteriores, sobre su fe en la libertad de pensamiento y de palabra y, por lo tanto, condena la actitud de ciertos gobiernos del Continente que han desposeído de sus cátedras, por meras razones políticas, a eminentes profesores de América, y hace votos porque muy pronto sean restablecidos en sus funciones de maestros, en bien de la juventud que ahora, más que nunca, necesita ser educada en los principios de la libertad y la justicia.

$\mathrm{v}$

Estudiada la ponencia del delegado por México, José Luis Martínez, la comisión encuentra que son de aprobarse en todos sus puntos las conclusiones a que llega, y por lo tanto, la comisión propone: 
$1^{\circ}$ Que se procure la formación, en cada uno de los países hispanoamericanos, de hemerotecas nacionales que concentren el acervo existente en ellos de revistas y periódicos literarios;

$2^{\circ}$ Que se interese a los especialistas, también, en la redacción de catálogos de las revistas y periódicos literarios de cada uno de los países hispanoamericanos;

$3^{\circ}$ Que se inicie la elaboración de índices clasificados y analiticos que sigan todos, de ser posible, el mismo método, de estas revistas y periódicos;

$4^{\circ}$ Que se promueva la investigación crítica y documental de los acervos literarios contenidos en el periodismo, e igualmente, la investigación histórica y crítica de los diferentes ciclos y sectores de este periodismo literario, $y$

$5^{\circ}$ Procurar la reedición total de las revistas más importantes, que constituyen preciosos documentos para el investigador y en no pocos casos, obras que conservan en su forma de cuerpos colectivos, excepcional interés histórico y literario.

Estudiada la proposición que presenta a este Congreso el delegado doctor Octavio Méndez Pereira, para que el Instituto de Literatura apoye la candidatura del doctor Antonio Sánchez de Bustamante, ante la Academia Sueca para el premio Nobel de la Paz, la comisión expresa que el Instituto indudablemente vería con gran simpatía que un cubano ilustre obtuviera tan preciado galardón; pero siente el escrúpulo de considerar que una iniciativa semejante está fuera del campo de sus estudios y trabajos, sobre todo cuando d Congreso ha resuelto no intervenir en la proposición de candidaturas al premio Nobel de Letras. 